\title{
Rodlet cells and other inflammatory cells of Phoxinus phoxinus infected with Raphidascaris acus (Nematoda)
}

\author{
Bahram Sayyaf Dezfuli ${ }^{1, *}$, Edi Simoni $^{1}{ }^{1}$ Remigio Rossi ${ }^{1}$, Maurizio Manera ${ }^{2}$ \\ ${ }^{1}$ Department of Biology, University of Ferrara, Via Borsari, 46, 44100 Ferrara, Italy \\ ${ }^{2}$ Faculty of Veterinary Medicine, University of Teramo, 64020 Nepezzano, Teramo, Italy
}

\begin{abstract}
Rodlet cells (RCs), and other inflammatory cells, namely eosinophile granule cells (EGCs), eosinophilic granulocytes and epithelioid cells in the liver, pancreas and peritoneal serosa of uninfected and naturally parasitized minnow Phoxinus phoxinus (Linnaeus, 1758), were studied by light and electron microscopy. Forty-eight minnows were examined and in 18 fishes encysted larvae of the nematode Raphidascaris acus (Bloch, 1779) were encountered, mainly in the pancreas. The number of larvae in the latter organ ranged from 2 to 46 . Nematode larvae were encapsulated by epithelioid granulomata, and these cells displayed typical epithelial characteristics such as desmosomes and tonofilaments. EGCs and RCs characteristically surrounded the reactive foci and were suggestive of an integrated inflammatory network involving both cell types. In many instances RCs were noticed at the periphery of the pancreas, beneath the peritoneal serosa, partially or entirely surrounded by mesothelial cells. In the latter situation partially damaged RCs were present in the splancnic cavity entirely surrounded but not truly phagocytized (no phagolysosome occurred) by mesothelial cells, which shared the same ultrastructural features of epithelioid cells. This phenomenon has never been described and may represent a peculiar turnover of RCs in the pancreas likely related to the high sensitivity to damage. A significant difference $(p<0.01)$ in the number of RCs between uninfected and parasitized fish was noticed in the liver and pancreas. The data suggest that RCs represent an inflammatory cell type closely linked to other piscine inflammatory cells, such as EGCs, epithelioid cells and mesothelial cells.
\end{abstract}

KEY WORDS: Rodlet cells · Inflammatory cells · Phoxinus phoxinus · Helminth infection · Ultrastructure Resale or republication not permitted without written consent of the publisher

\section{INTRODUCTION}

Rodlet cells (RCs) have conspicuous inclusions, a distinctive cell cortex and have been described in different organs of marine and freshwater fish (Barber et al. 1979, Viehberger \& Bielek 1982). The nature of RCs remains controversial; structure and distribution of these cells has led to speculation regarding their function (Leino 1996). Some authors suggested that the 'secretory granules' of RCs are the infective stage of a protozoan parasite (Rhabdospora thelohani) and that

*E-mail: dzb@dns.unife.it these granules contain genetic material (Barber et al 1979, Bielek \& Viehberger 1983). Other authors using a variety of cytochemical tests for nucleic acids, however, failed to detect either DNA or RNA in the RCs (Morrison \& Odense 1978, Leino 1982).

RCs have been suggested to be involved in functions such as osmoregulation (Mattey et al. 1979) and ion transportation (Morrison \& Odense 1978) or to act as secretory cells (Mattey et al. 1979, Leino 1996). According to Leino (1996), RCs react to the occurrence of ectoparasites on the epithelial surface and the secretion of these cells exerts antibiotic activity. Very few papers dealing with the relationship between RCs and endoparasitic helminths have been published (Reite 
1997, Dezfuli et al. 1998); furthermore, no previous report has been found on the interaction between RCs and the piscine inflammatory system.

Here, we provide data describing: (1) the ultrastructure of RCs and other inflammatory cells, namely eosinophile granule cells (EGCs), eosinophilic granulocytes and mesothelial/epithelioid cells of Phoxinus phoxinus infected with larvae of Raphidascaris acus; (2) the relationship between above-mentioned cells with parasite larvae; (3) the role of RCs in the piscine inflammatory system; and (4) the turnover of RCs involving mesothelial cells.

\section{MATERIALS AND METHODS}

Forty-eight specimens of minnow Phoxinus phoxinus were collected (on several occasions) by electrofishing from a stream in the province of Padua (North Italy). The live fish were brought to the laboratory and examined for the presence of helminth parasites. Digestive tract and associated organs were isolated from the rest of the body, examined for parasites, and fixed and embedded for light and electron microscopy.

Pieces of tissue up to $7 \mathrm{~mm}$ in diameter were fixed in $2 \%$ glutaraldehyde in $0.1 \mathrm{M}$ cacodylate buffer, postfixed in $1 \%$ osmium tetroxide in the same buffer for $2 \mathrm{~h}$, dehydrated in graded ethanol, transferred to propylene oxide and embedded in an Epon-Araldite mixture. Semithin sections were cut on a Reichert Om U2 ultramicrotome with glass knives and stained with azure-A methylene blue. Ultrathin sections were stained in a $50 \%$ alcohol uranyl acetate solution and lead citrate, and examined in a Hitachi $\mathrm{H}-800$ electron microscope. Light photomicrographs were obtained with a Leitz photomicroscope. For comparative purposes, the tissues of the intestine and visceral organs of 10 uninfected minnows were similarly processed.

Biometrics methods were applied to 18 infected and 18 uninfected minnows. RCs were counted in 10 randomly selected microscopic fields of $513679{\mu \mathrm{m}^{2}}^{2}$ in each of 36 fish. Analysis of variance (nested ANOVA) was applied to square-root-transformed data according to Lison (1961). Identification of the nematode larvae was based on descriptions provided in Moravec (1994).

\section{RESULTS}

The liver and pancreas of 18 out of 48 minnows were infected with larvae of Raphidascaris acus. In 18 fish analysed the intensity of infection ranged from 2 to 46 larvae per fish $(20 \pm 3)$.

The diameters of encysted larvae ranged from 28 to $45.5 \mu \mathrm{m}(32 \pm 1.37 \mu \mathrm{m}, \mathrm{n}=21)$ and macroscopically appeared as white-yellowish nodules in the liver, pancreas and mesenteric serosa. The larvae were located mainly beneath the serosa of the 2 abdominal organs. There were no signs of acute reaction to the parasites, suggesting a well-established, chronic reaction.

\section{Histopathological observations of parasitized fish (light microscopy)}

In resin sections of liver and pancreas the nodules contained 1 or more nematode larvae (Fig. 1). The larvae were surrounded by a concentric corona of epithelioid cells, 2 to 4 cells in thickness. The edges of the single epithelioid cells were not visible and appeared syncytial. Cells surrounding the parasite larva appeared much darker than those in the outer part of the nodule (Fig. 2). Despite the difference in staining, no definite separation between the host epithelioid cells and the parasite was evident. At least 2 types of cells were recognised: at the periphery of the epithelioid corona voluminous, round, granular cells whose cytoplasm contained many homogeneous dark granules displacing the nuclei at the periphery of the cells (Figs. 1 \& 2); and RCs located beneath the mesothelium, or at the periphery of the epithelioid foci (Fig. 1).

The infected liver maintained its general features without fibrosis due to the nematode-induced granulomata, but the hepatocytes, lining the granulomata, displayed hydropic degeneration (swelling) with slightly foamy cytoplasm.

\section{Ultrastructural observations}

$$
\text { Epithelioid cells }
$$

The epithelioid corona surrounding a nematode larva was composed of elongated macrophages (e.g., epithelioid cells). Their nucleus was rich in euchromatin (Fig. 3) and their cytoplasm contained many filaments, free ribosomes, and swollen mitochondria (Fig. 4). Plasmalemma made cellular projections which seemed to connect the adjacent cells (Fig. 3); moreover, small vesicles were noticed in these cells. The intercellular connections were fortified by means of abundant desmosomes (Figs. 3 \& 4). Typical desmosomes consisted of 2 subplasmalemmar attachment plaques with tonofilaments converging to the latter and an intermediate line interposed between the 2 plasmalemmas. The innermost epithelioid cells layer were electron-dense and displayed finger-like projections which penetrated the outermost cuticular layer of larval nematodes. These projections (filopodia) greatly increased the interface between host cells and parasite cuticle (Fig. 5). 


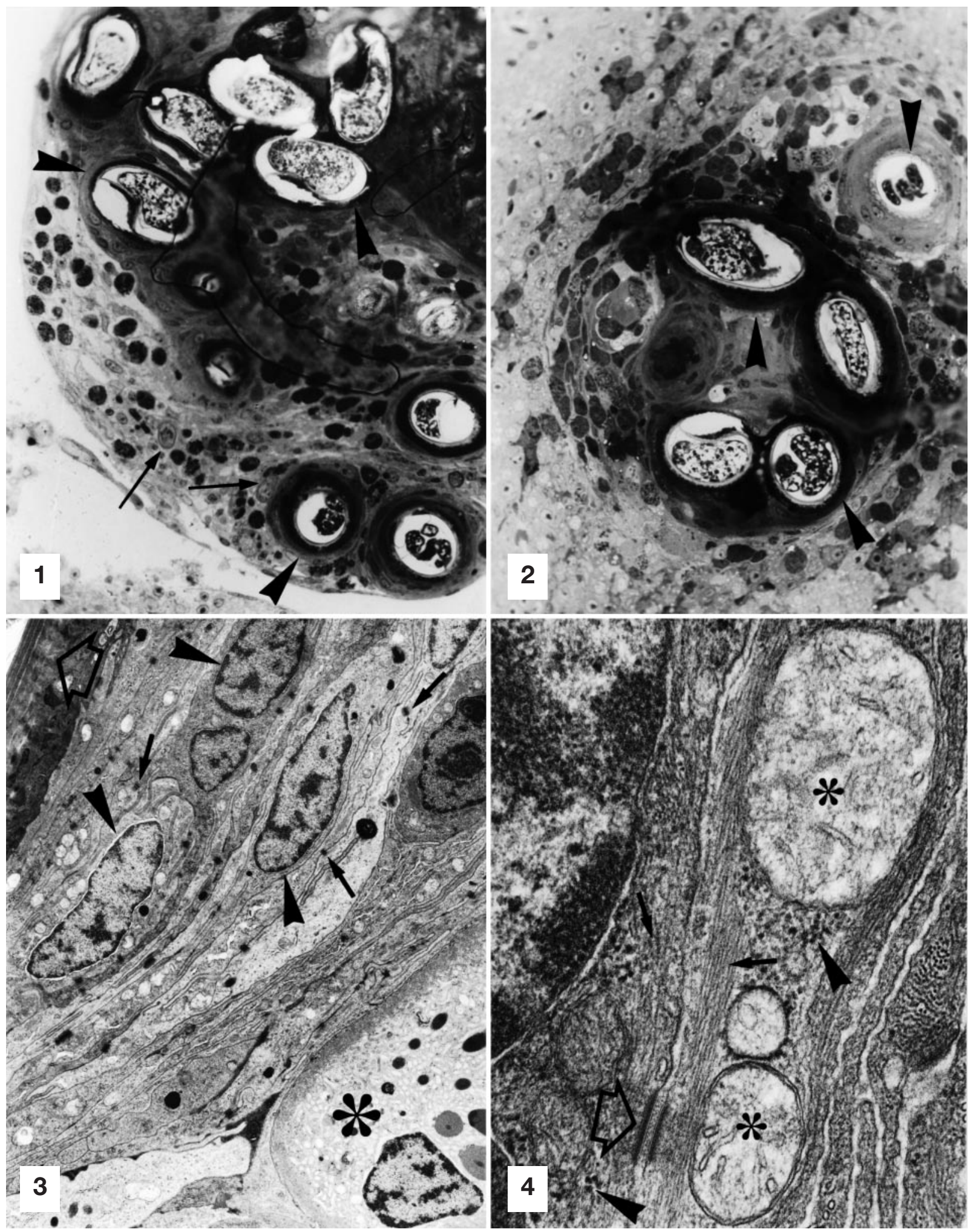

Figs. 1 to 4. Phoxinus phoxinus infected with Raphidascaris acus. Fig. 1. Semithin section of liver of $P$. phoxinus with encysted larvae of $R$. acus (arrowheads). Note the occurrence of rodlet cells (arrows) among granulocytes. $\times 460$. Fig. 2. Semithin section of pancreas with encysted larvae of nematode (arrowheads). Note denser staining of cells near the parasite than of cells more distant from the nodules. $\times 400$. Fig. 3 . Electron micrograph showing epithelioid cells (arrowheads) around the parasite larva in the liver (open arrow) and a rodlet cell (asterisk) at the periphery of the nodule. Note the occurrence of many desmosomes among epithelioid cells (arrows). $\times 5000$. Fig. 4. High magnification of epithelioid cell in the liver. Note occurrence of swollen mitochondria displaying cristolysis (asterisks), intermediate filaments (arrows), and free ribosomes (arrowheads). Note the desmo- 

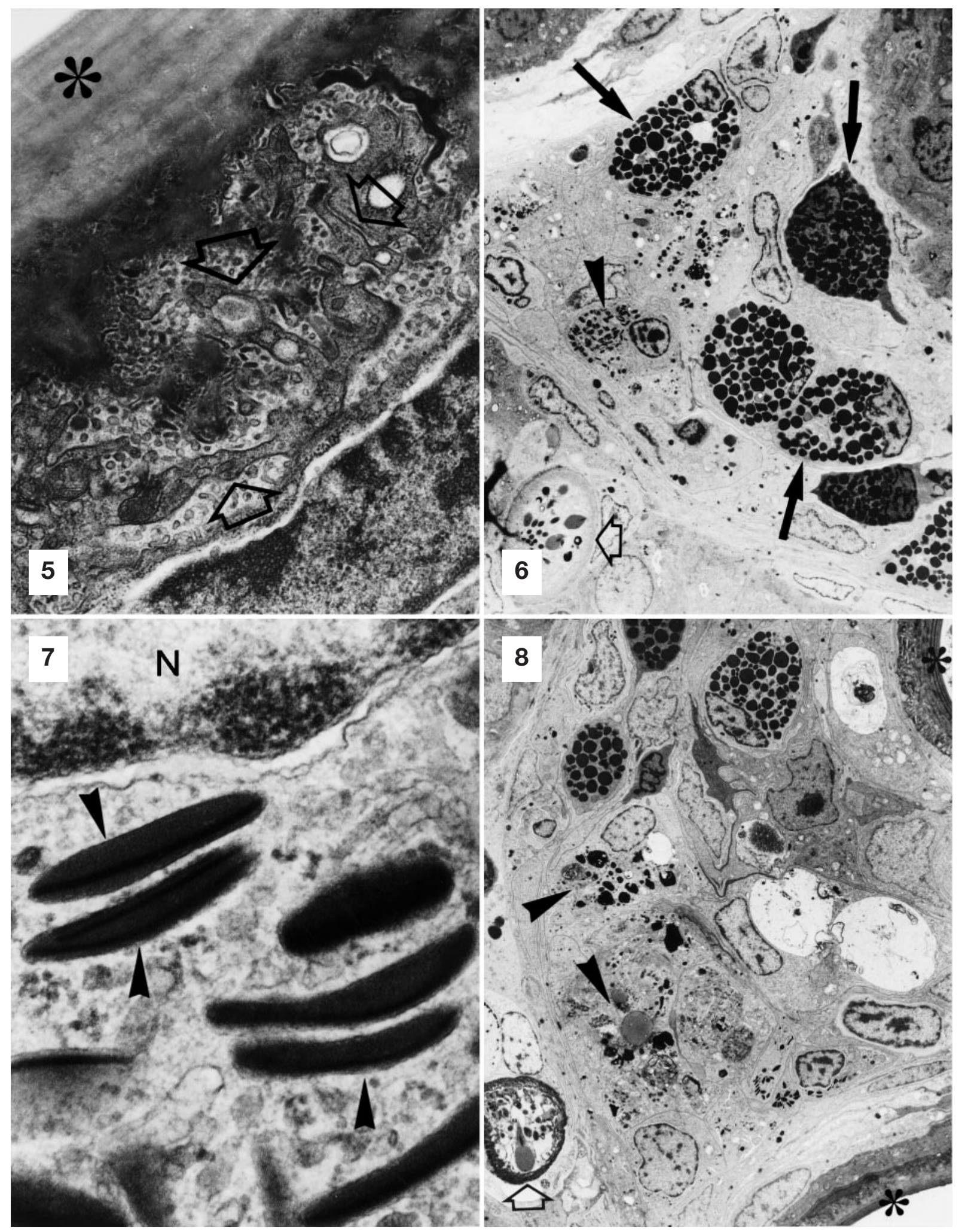

Figs. 5 to 8. Phoxinus phoxinus infected with Raphidascaris acus. Fig. 5. Micrograph shows encysted larva of $R$. acus in pancreas. Connection (open arrows) between epithelioid cell and larval tegument (asterisk) can be seen. $\times 22860$. Fig. 6 . Host granulocytes near 2 nematode larvae. Arrows indicate eosinophilic granule cells, arrowhead shows eosinophile, and open arrow shows a rodlet cell. $\times 2400$. Fig. 7 . High magnification of eosinophile in host liver. Note rod-shaped aspect of granules (arrowheads). $\mathrm{N}$ : nucleus. $\times 71350$. Fig. 8. Two nematode larvae (asterisks) encysted in liver encircled with host cells. Occurrence of macrophages (arrowheads) are evident; open arrow shows a rodlet cell. $\times 2530$ 


\section{Granular cells}

The granular cells surrounding the epithelioid corona contained numerous polymorphic, dense granules that displaced the nucleus to the periphery (Fig. 6). They were recognised as EGCs. There was also another type of granular cell scattered among EGCs and RCs (Fig. 6). They contained smaller granules than those of the EGCs, and displayed unique features, being elongated, rod-shaped and possessing an elongated, electron-dense, lamellar core (Fig. 7). The rest of the granule displayed an amorphous, fine granular matrix. Plasmalemma projections (pseudopodia) also were observed in these granulocytes. Both EGCs and the other type of granular cell occasionally appeared to have undergone degeneration, ranging from acute swelling to cellular lysis and dispersion of granules into the interstitial. Macrophages also were observed scattered among granular cells (Fig. 8).

\section{Rodlet cells}

A greater number of RCs were observed in the biliary ducts and visceral organs of parasitized fish than in healthy fish ( $p<0.01$, Table 1$)$. These cells occurred especially around the granulomata (Fig. 9), where they were scattered among granular cells, hepatocytes, pancreatic cells, epithelioid cells, and beneath hepatic sinusoids (Fig. 10) and the peritoneal mesothelium (Figs. 11 \& 12).

Sub-mesothelial RCs were typically covered by mesothelial cells, even when RCs protruded from the outer surface of visceral organs into the peritoneum suggesting a strong sealing action by means of mesothelial cells (Fig. 11). Mainly in damaged tissue of visceral organs, mesothelial cells formed junction complexes with the RCs (Fig. 14) with some in the discharging phase (Fig. 13).

Two types of RCs (likely different developing stages) were recognised. One type, which formed the vast majority, contained the typical club-shaped formations (so called rodlets) with an elongated crystalline core

Table 1. Nested ANOVA performed on 'square root' transformed data

\begin{tabular}{|lrrrr|}
\hline Source of variation & SS & df & MS & F-test \\
\hline Infection state & 6.22 & 1 & 6.22 & $12.2^{*}$ \\
Fishes within the & 4.08 & 8 & 0.51 & \\
$\quad$ same group & & & & \\
Tissue areas & 37.62 & 90 & 0.418 & \\
Total & 47.92 & 99 & & \\
${ }^{*} \mathrm{p}<0.01$ & & & & \\
\hline
\end{tabular}

(Figs. 9, 10 \& 11) in which the cytoplasm appeared vesicular and foamy (Fig. 13). The second, less common, type of RCs had few rodlets. These RCs possessed a subplasmalemma fibrillar capsule. Their nuclei were round to oval with an irregular outline, often occupied the basal portion of the cell, and were characterised by randomly distributed zones of heterochromatin. Regarding the cell organelles, some Golgi apparatuses, rough endoplasmic reticulum and in many instances a high number of round-elongated mitochondria occurred at the apex of the RC (Figs. 12 \& 13). Two methods of discharge by the RCs were observed. The first type pertained to RCs inhabiting the epithelia (e.g., biliary ducts, peritoneal serosa). In this group, the apical part of the RC opened into the lumen, and the cell discharged its contents (Fig. 13). The second type of release was seen in RCs localized in the interstitial zones of pancreas, liver and body cavity (Fig. 15). Here the RC opened laterally and released its contents.

A very peculiar phenomenon was documented for RCs in the pancreas, namely, the encapsulation of the RC by epithelial-like cells (likely mesothelial cells) (Figs. 15 \& 16). Mesothelial cells surround the transperitoneal protruding RCs and from here this peculiar 'cell association' proceeded into the peritoneal cavity. Herein, usually the lateral part of the mesothelial cell was opened and permitted the extrusion of the RC contents (Fig. 15). An epiplasmalemmar space lined by mesothelial cell plasmalemma from one side and RC plasmalemma from the other side was detected. Some mesothelial cell cytoplasmic projections spread out in this space (Fig. 16). In some instances within the peritoneum 2 or even 3 mesothelial cells encircled a RC in disintegration (Fig. 16).

\section{Hepatic cells}

As mentioned above, hepatocytes underwent degenerative changes, particularly near the nematode larvae, and it was histologically recognisable as hydropic degeneration (cellular oedema). Hepatocytes displayed swelling and cytoplasmic pallor due to excess water uptake which diluted the cytoplasmic matrix (Fig. 12). Mitochondria appeared dilated and lacked in welldeveloped cristae (mitochondrial swelling and cristolysis). Moreover, the hepatocytes abounded in glycogen, and their nuclei were very large and rich in euchromatin with only a thin rim of heterochromatic against the inner membrane of the nuclear envelope. Nucleoli were prominent and had an open or reticular nucleonema; in other words, they had a branching, anastomosing, coarse, thread-like structure, the nucleolonema, which entrapped, in their own meshes, rounded structures known as 'pars amorpha' (Fig. 12). 

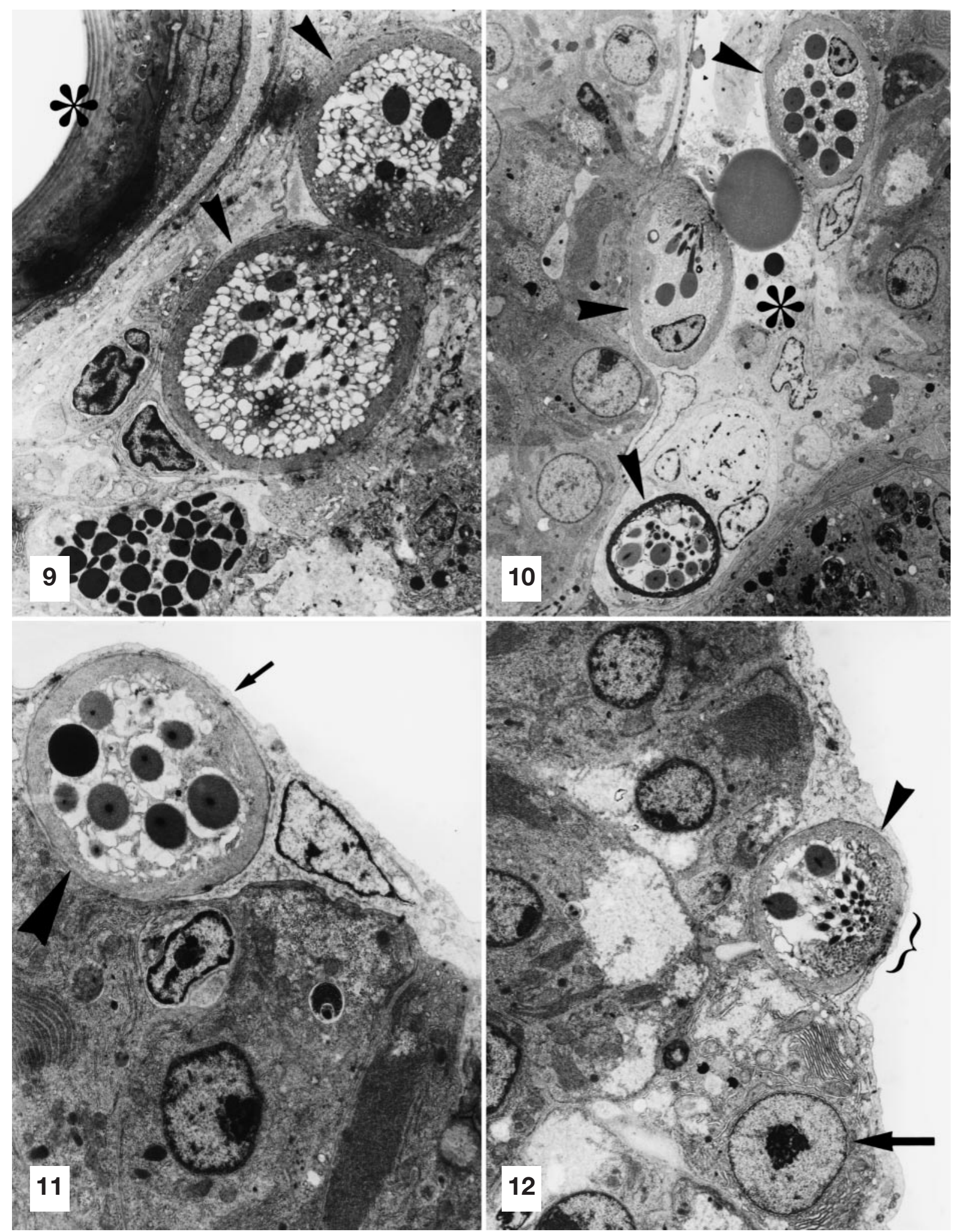

Figs. 9 to 12. Phoxinus phoxinus infected with Raphidascaris acus. Fig. 9. Micrograph shows the presence of 2 rodlet cells (arrowheads) in the pancreas near the $R$. acus larva (asterisk). $\times 4410$. Fig. 10. Note the presence of 3 rodlet cells (arrowheads) in liver; asterisk indicates lumen of hepatic sinusoid. $\times 2670$. Fig. 11. Rodlet cell (arrowhead) is enclosed by mesothelial cell of liver (arrow). $\times 5760$. Fig. 12. Occurrence of rodlet cell beneath the surface of liver. Note the junctional complexes (parenthesis); arrow 

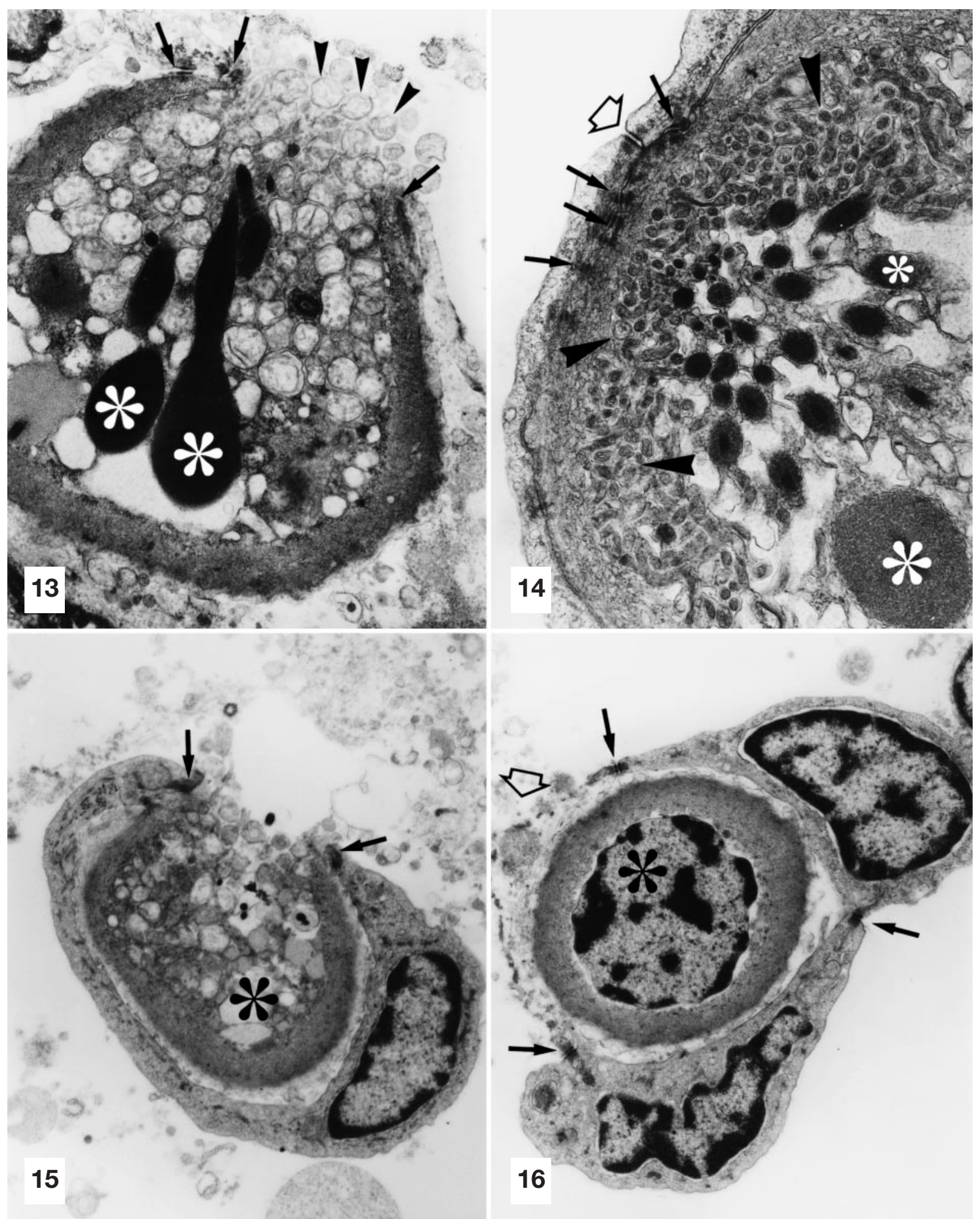

Figs. 13 to 16. Phoxinus phoxinus infected with Raphidascaris acus. Fig. 13. Discharging rodlet cell still anchored to the surface of liver of infected P. phoxinus. Note desmosomes (arrows) between rodlet cell and adjacent cells. Arrowheads show mitochondria and white asterisks indicate rodlets. $\times 14250$. Fig. 14. Two mesothelial cells enclose protruding rodlet cells in liver. Note the presence of desmosomes (open arrow) between the 2 mesothelial cells and also desmosomes between them and a rodlet cell (arrows). Arrowheads indicate mitochondria, and white asterisks show rodlets. $\times 18410$. Fig. 15 . A rodlet cell (asterisk) transported into the peritoneal cavity encircled by a mesothelial cell, displays discharging activity into the peritoneal cavity. Lateral opening of rodlet cell and occurrence of junctional complexes among the 2 cells are visible (arrows). $\times 10500$. Fig. 16. A rodlet cell (asterisk) in peritoneal cavity is encircled by 3 mesothelial cells, one of which has undergone lysis (open arrow). Note the occurrence of desmo- 


\section{Pancreatic cells}

The pancreas, probably due to its function (high content of hydrolytic enzymes), underwent the major pathological changes involving organ cells and interstitial structural features (Figs. 2, 5 \& 9). Zymogen granules were pleomorphic and scattered among the interstitial. Many lamellar granules, originating from the previously described granulocytes, were observed between the zymogen granules.

\section{DISCUSSION}

Many species of nematode parasites are known to infect juvenile and adult fish (Moravec 1994). Larval nematode migration and encapsulation within body tissues and visceral organs often cause the development of lesions described as 'fibro-granulomatous', although in many instances no host inflammatory reaction is elicited (Ferguson 1989). Granulomatous reactions have been observed frequently in fish as a reaction against bacteria, fungi, algae, protozoa and other infective agents (Ferguson 1989, Roberts 1989). Histologically, fish granulomata are inflammatory foci of epithelioid cells that closely resemble mammalian granulomata (Ferguson 1989, Roberts 1989). These epithelioid cells are typically transformed macrophages, whose main role is to engulf foreign bodies. The epithelioid cells in the fish tissues we examined contained desmosomes, organelles known to occur only in epithelial cells (Ghadially 1988).

Findings similar to these have been reported by Noga et al. (1989) and Karanis \& Taraschewski (1993). Noga et al. (1989) pointed out the striking resemblance between epithelioid cells and mesothelial cells and suggested that piscine epithelioid cells may represent an alternative type of epithelial inflammatory cell. More recently Lopez-Doriga \& Martinez (1998) reported that epithelial cells in fish perform a defensive function against the fungus Saprolegnia spp. Rather than phagocytising the hyphae of this fungal parasite, the epithelial cells encircled and encapsulated the hyphae, evidently halting or retarding their growth. We have observed this phenomenon in the pancreas of minnows. Here the epitheliallike cells surround the $\mathrm{RC}$ and maintain this association as the cells move into the splancnic cavity. The epithelial-like cells are presumably mesothelial cells and this phenomena represents an effective sealing action by the pancreatic mesothelium. Interestingly, the RC discharging activity occurs almost exclusively where degenerative damage has occurred, and this appears to inhibit a mesothelial cell's sealing action.

The nature of EGCs is still a matter of debate and several hypotheses have been proposed regarding their functional role (Sire \& Vernier 1995, Secombes 1996). The most widely accepted hypothesis is that, in view of their homology with mammalian mast cells and globular leukocytes (Reite \& Evensen 1994, Reite 1998), EGCs are part of the host's inflammatory response. Mammalian mast cells (MCs) are involved in acute inflammation, the modulation of cellular growth, and leukocyte differentiation and activation (Leon et al. 1994, Galli 1997). According to Reite (1998), MCs are thought to originate from stem cells in the bone marrow which migrate out of the bone and undergo differentiation. As flogistic stimuli occur within the mucosa, the MCs enter the epithelia from subepithelial tissue layers and become globular leukocytes (i.e. intraepithelial mucosal mast cells). This phenomenon occurs in mammals but also has been reported in fish. In mammals and birds parasitized by intestinal helminths, extensive MC recruitment occurs at sites of infection (Murray 1972, Gray 1976). Likewise, EGCs in fish occur at inflammation sites caused by parasitic infection (Ferguson 1989, Reite 1998).

We propose that the granulocytes encountered in Phoxinus phoxinus are eosinophils. Reinforcing this characterization is the anti-parasite activity reported by Ainsworth (1992) for fish eosinophiles, and the fact that goldfish eosinophiles possess similar crystalloid granules (Fujimaki \& Isoda 1990). This investigation has documented the relationship that exists between eosinophiles and EGCs, and our data suggest that in minnows the EGCs control a complex reactive/reparative cell network as previously reported in mammals (Miolo 1998).

RCs occurring at the inflammatory foci of parasitic infections have been reported previously (Leino 1996, Dezfuli et al. 1998); however, their nature, functional role, and even their organism affinity is still a matter of considerable debate. More than a hundred years ago, Thèlohan (1892) originally described RCs as being parasites of fish. Within the last decade, RCs have been variously described as protozoa (Viehberger \& Bielek 1982, Richards et al. 1994), host cells representing a special type of leukocyte or as epithelial secretory cells (Della Salda et al. 1998, Dezfuli et al. 1998). Phagocytosis of RCs by mean of macrophages and neutrophils has been reported by Richards et al. (1994) as evidence of the $\mathrm{RC}$ 's parasitic nature. In the present study, the encapsulation of RCs by mesothelial cells was seen more frequently than phagocytosis by macrophages. Our present observations suggest that the 'old or degenerated $\mathrm{RC}^{\prime}$ migrates into the peritoneal cavity with an encircling sheath of mesothelial cells, and this cell formation is maintained all the way to the RC's final destination, the fish body cavity. We suggest that this kind of cell migration may be an essential step for the removal of senescent and degenerative RCs from the fish pancreas. 
Leino (1996) has suggested that RCs could be 'stimulated by some substance produced as a result of tissue injury or related factors and is reminiscent of leukocyte responses to various chemotactic stimulus'. We propose that RCs play an important role in the fish inflammatory response and that their recruitment may be regulated by chemical signals emanating from EGCs. RCs display structural features very similar to those of leukocytes and to those of epithelial cells, and we believe that these mysterious cells are part of the fish inflammatory-reactive network.

Acknowledgements. Thanks are due to William J. Poly from Southern Illinois University for the English revision of the final draft of this manuscript and to the Centre of Electron Microscopy, University of Ferrara, for technical help. This investigation was supported by grants from the Italian Ministry of the University and Scientific Research and Technology.

\section{LITERATURE CITED}

Ainsworth AJ (1992) Fish granulocytes: morphology, distribution, and function. Annu Rev Fish Dis 1:123-148

Barber DL, Mills Westermann JE, Jensen DN (1979) New observation on the rodlet cell (Rhabdospora thelohani) in the white sucker Catostomus commersoni (Lacépède): LM and EM studies. J Fish Biol 14:277-284

Bielek E, Viehberger G (1983) New aspects on the 'rodlet cell' in teleosts. J Submicrosc Cytol 15:681-694

Della Salda L, Manera M, Biavati S (1998) Ultrastructural features of associated rodlet cells in the renal epithelium of Sparus aurata L. J Submicrosc Cytol Pathol 30:189-192

Dezfuli BS, Capuano S, Manera M (1998) A description of rodlet cells from alimentary canal of Anguilla anguilla and their relationship with parasitic helminths. J Fish Biol 53:1084-1095

Ferguson HW (1989) Systemic pathology of fishes. Iowa State University Press, Ames

Fujimaki Y, Isoda M (1990) Fine-structural study of leukocytes in the goldfish, Carassius auratus. J Fish Biol 36: 821-831

Galli SJ (1997) The mast cell: a versatile effector cell for a challenging world. Int Arch Allergy Immunol 113:14-22

Ghadially FN (1988) Ultrastructural pathology of the cell and matrix, Vol I-II. Butterworths, London

Gray JS (1976) The cellular response of the fowl small intestine to primary and secondary infections of the cestode Raillietina cesticillus (Molin). Parasitology 73:189-204

Karanis P, Taraschewski H (1993) Host-parasite interface of Caryophyllaeus laticeps (Eucestoda: Caryophyllidae) in three species of fish. J Fish Dis 16:371-379

Leino RL (1982) Rodlet cells in the gill and intestine of Catostomus commersoni and Perca flavescens: a comparison of their light and electron microscopic cytochemistry

Editorial responsibility: Wolfgang Körting,

Hannover, Germany with that of mucous and granular cells. Can J Zool 60: $2768-2782$

Leino RL (1996) Reaction of rodlet cells to a myxosporean infection in kidney of the bluegill, Lepomis macrochirus. Can J Zool 74:217-225

Leon A, Buriani A, Dal Toso R, Fabris M, Romanello S, Aloe L, Levi-Montalcini R (1994) Mast cell synthesise, store and release Nerve Growth Factor. Proc Natl Acad Sci 91: $3739-3743$

Lison L (1961) Statistica applicata alla biologia sperimentale. Casa Editrice Ambrosiana, Milano

Lopez-Doriga MV, Martinez JL (1998) Ultrastructure of fish cells involved in cellular defences against Saprolegnia infections: evidence of non-leucocytic nature. Dis Aquat Org 32:111-117

Mattey DL, Morgan M, Wright DE (1979) Distribution and development of rodlet cells in the gills and pseudobranch of the bass, Dicentrachus labrax (L). J Fish Biol 15:363-370

Miolo A (1998) Il mastocita nella biologia della cicatrizzazione cutanea. Inn Vet Med 2:10-16

Moravec F (1994) Parasitic nematodes of freshwater fishes of Europe. Academia, Praha

Morrison CM, Odense PH (1978) Distribution and morphology of the rodlet cell in fish. J Fish Res Board Can 35: 101-116

Murray M (1972) Immediate hypersensitivity effector mechanisms. II. In vivo reactions. In: Soulsby (ed) Immunity to animal parasites. Academic Press, New York, p 155-199

Noga EJ, Dykstra MJ, Wright JF (1989) Chronic inflammatory cells with epithelial cell characteristics in teleost fishes. Vet Pathol 26:429-437

Reite OB (1997) Mast cells/eosinophilic granule cells of salmonids: staining properties and responses to noxious agents. Fish Shellfish Immunol 7:567-584

Reite OB (1998) Mast cells/granule cells of teleostean fish: a review focusing on staining properties and functional responses. Fish Shellfish Immunol 8:489-513

Reite OB, Evensen $\varnothing$ (1994) Mast cells in the swimbladder of Atlantic salmon Salmo salar: histochemistry and responses to compound 48/80 and formalin-inactivated Aeromonas salomonicida. Dis Aquat Org 20:95-100

Richards DT, Hoole D, Arme C, Lewis JW, Ewens E (1994) Phagocytosis of rodlet cells (Rhabdospora thelohani Laguesse, 1895) by carp (Cyprinus carpio L.) macrophages and neutrophils. Helmintologia 31:29-33

Roberts RJ (1989) Fish pathology. Bailliere Tindall, London

Secombes CJ (1996) The nonspecific immune system: cellular defences. In: Iwama G, Nakanishi T (eds) The fish immune system. Fish physiology series, Vol 15. Academic Press, San Diego, p 63-103

Sire MF, Vernier JM (1995) Partial characterization of eosinophilic granule cells (EGCs) and identification of mast cells of the intestinal lamina propria in rainbow trout (Oncorhynchus mykiss). Biochemical and cytochemical study. Biol Cell 85:35-41

Thèlohan P (1892) Sur les sporozoares indetermines parasites des poissons. J Anat Physiol 28:163-171

Viehberger E, Bielek E (1982) Rodlet cells: gland cells or protozoan? Experientia 38:1216-1218

Submitted: February 8, 2000; Accepted: August 17, 2000 Proofs received from author(s): October 18, 2000 